\title{
SYNERGISTIC EXPLOITATION OF GEOINFORMATION METHODS FOR POST- EARTHQUAKE 3D MAPPING OF VRISA TRADITIONAL SETTLEMENT, LESVOS ISLAND, GREECE
}

\author{
N. Soulakellis ${ }^{1, *}$, S. Chatzistamatis ${ }^{2}$, C. Vasilakos ${ }^{1}$, G. Tataris ${ }^{1}$, A. Papakonstantinou ${ }^{1}$, D. Kavroudakis ${ }^{1}$, K. Topouzelis ${ }^{3}$, O. \\ Roussou ${ }^{1}$, Ch. Kalloniatis ${ }^{2}$, E. E. Papadopoulou ${ }^{1}$, K. Chaidas ${ }^{1}$, P. Kalaitzis ${ }^{1}$ \\ ${ }^{1}$ Dept. of Geography, University of the Aegean, Mytilene, Greece - nsoul@aegean.gr \\ ${ }^{2}$ Dept. of Cultural Technology and Communication, University of the Aegean, Mytilene, Greece - (stami, chkallon)@aegean.gr \\ ${ }^{3}$ Dept. of Marine Sciences, University of the Aegean, Mytilene, Greece - ktopo@ aegean.gr
}

KEY WORDS: Post-earthquake 3D mapping, Lesvos earthquake, UAV, Laser Scanning, SfM method

\begin{abstract}
:
The aim of this paper is to present the methodology followed and the results obtained by the synergistic exploitation of geo-information methods towards 3D mapping of the impact of the catastrophic earthquake of June $12^{\text {th }} 2017$ on the traditional settlement of Vrisa on the island of Lesvos, Greece. A campaign took place for collecting: a) more than 150 ground control points using an RTK system, b) more than 20.000 high-resolution terrestrial and aerial images using cameras and Unmanned Aircraft Systems and c) 140 point clouds by a 3D Terrestrial Laser Scanner. The Structure from Motion method has been applied on the high-resolution terrestrial and aerial photographs, for producing accurate and very detailed 3D models of the damaged buildings of the Vrisa settlement. Additionally, two Orthophoto maps and Digital Surface Models have been created, with a spatial resolution of $5 \mathrm{~cm}$ and $3 \mathrm{~cm}$, respectively. The first orthophoto map has been created just one day after the earthquake, while the second one, a month later. In parallel, 3D laser scanning data have been exploited in order to validate the accuracy of the 3D models and the RTK measurements used for the geo-registration of all the above-mentioned datasets. The significant advantages of the proposed methodology are: a) the coverage of large scale areas; b) the production of 3D models having very high spatial resolution and c) the support of post-earthquake management and reconstruction processes of the Vrisa village, since such 3D information can serve all stakeholders, be it national and/or local organizations.
\end{abstract}

\section{INTRODUCTION}

An earthquake is a very crucial case of natural hazards, having the following characteristics: a) it cannot be predicted; b) only few seconds of a strong shake can cause enormous damage in large areas; c) it can affect all aspects of society; d) its effects can last for many years; and e) the correct management of an earthquake risk relies on close cooperation between different organizations at different levels. Additionally, the postearthquake situation is extremely complicated, especially few hours or days after the main earthquake, where: a) the buildings are highly vulnerable to aftershocks; b) all streets are not accessible; c) seismic activity continues to produce several strong aftershocks affecting more the most damaged buildings; d) relief operations are in action by several organizations; and e) most people are frightened and some in panic.

The post-earthquake damage assessment and management requires reliable, accurate and high-resolution spatial information especially in cases where building damages have occurred (Wegscheider et al., 2013). Most often earth observation and geoinformation provides reliable 2D spatial information and more rarely, only for very exceptional cases such as buildings with archaeological interest, 3D information is generated in order to document the effects of the earthquake on them.

Despite the fact that geoinformation is rapidly expanding to several disciplines of both human and natural sciences, there is no robust methodology to apply in urgent situations such as after an earthquake for the creation of 3D models capturing its effects at a village scale.

Orthophoto maps and Digital Surface Models (DSM) can be produced, by terrestrial and/or aerial high-resolution 2D imagery taken after an earthquake, due to the very recent advances in the fields of computer vision and photogrammetry in combination with the improvements in data processing power. The Structure from Motion (SfM) algorithm has improved the quality of 3D data that can be derived from overlapping imagery by incorporating advancements in soft-copy triangulation and image-based terrain extraction algorithms (Westoby et al., 2012).

According to Adams and Friedland (2011), Unmanned Aerial Vehicles (UAVs) have been utilized with great potential following the 2009 L'Aquila, 2010 Haiti and 2011 Japan earthquakes and each event presented different opportunities and lessons that will mold the promising future of UAV usage for imagery collection in disaster management and monitoring. Even more recently Dominici et al. (2017), mention that recent technological advantages make UAV-based photogrammetry highly suitable for surveys in a geo-hazard context, as in a postearthquake scenario, and its advantages may be summarized as follows: i. safety: no risk for operators; ii. possibility to survey inaccessible zones; iii. high-resolution photographs; iv. speed of survey and elaboration; and v. repeatability and economic convenience. Additionally, very precise 3D information derives directly by the use of specially designed instruments; namely Laser Scanners, terrestrial, airborne or mobile ones. A Terrestrial Laser Scanner (TLS) allows collecting accurately and in high

* Corresponding author 
resolution dense point clouds of the surface of any object to be reconstructed. This is very useful for post-earthquake damage assessment where a morphological investigation is crucial. Field acquisitions with TLSs devises are, in addition, very fast, and they can be made in safe conditions.

This article describes the methodology followed after the strong Lesvos 12 June 2017 (Mw=6.3) earthquake which has heavily damaged the building stock of Vrisa traditional settlement covering an area of approximately $0.3 \mathrm{Km}^{2}$. The damages where widespread and about $80 \%$ of its buildings, most of them traditional stone masonry residential constructions built by the end of the $19^{\text {th }}$ century, were affected.

\section{STUDY AREA - LESVOS, JUNE $12^{\mathrm{TH}} 2017\left(\mathrm{M}_{\mathrm{w}}=6.3\right)$ EARTHQUAKE}

The North Aegean region is a very tectonically active area, dominated by several active faults and frequent seismic activity. According to Chatzipetros et al. (2013), the region of northeastern and eastern Aegean Sea is controlled by a multitude of factors, which cause the formation, activation, or reactivation of many faults, most of which do not outcrop on land. Geodynamically, the region accommodates shear motion transferred from the east and at the same time undergoes the $\sim \mathrm{N}$ $\mathrm{S}$ extension of the back-arc Aegean Sea. More specifically, Lesvos island is dominated by active faults and diachronically attracts the interest of geoscientists to apply innovative geoinformation and remote sensing methodologies for its study (Novak and Soulakellis, 2000; Soulakellis et al., 2006).

On 12 June 2017 (UTC 12:28:38.26) a magnitude Mw 6.3 earthquake occurred offshore the SE coast of Lesvos island in NE Aegean Sea, which was widely felt, caused one fatality, and partially ruined the village of Vrisa on the south-eastern coast of the island. The heavy damages in the village of Vrisa can be attributed to the following factors: a) it lies at a short distance $\sim 5$ $\mathrm{km}$ from the western edge of the fault, even though its distance from the hypocentre is $\sim 23 \mathrm{~km}$; b) it lies above and at a close distance to the slip patch, e.g. the locus of the major slip; c) it experienced forward rupture directivity, and finally d) it lies on a pile of alluvia sediments, which, from the geological map, are estimated to be at least $220 \mathrm{~m}$ in thickness. No strong motion records are available close to Vrisa, and the closest station (e.g. PRK) recorded a PGA $36.8 \mathrm{~cm} / \mathrm{s} 2(\sim 0.04 \mathrm{~g})$ in the E-W horizontal component (Kiratzi, 2018). According to Lekkas et al. (2017), very heavy structural damage was observed in the western part of Vrisa, while its eastern part remained intact. The geological and geomorphological setting along with the building characteristics have been identified as factors controlling the spatial distribution of building damage. Specifically, the combination of highly vulnerable old structures founded on alluvial deposits and on slopes in an area bounded by significant faults in combination with probable directivity phenomena resulted in destruction.

Most of Vrisa buildings were damaged, several collapsed, while many were heavily damaged, reported dangerous and/or unrepairable. Monument constructions, such as post-Byzantine churches suffered severe static effects. Fewer damages were widespread throughout the island (reported in at least 12 villages).

\section{METHODOLOGY}

The methodology followed, in order to achieve high resolution and accurate 3D models at three different scales: i. village-scale; ii. street-scale; and iii. building-scale of the Vrisa settlement, is presented in Figure 1.
The data acquisition stage started on June $13^{\text {th }}$ (less than $24 \mathrm{hrs}$ after the earthquake) and lasted one month, involving several geoinformation data acquisition and processing methods and techniques: a) Real Time Kinematics measurements, b) high resolution aerial image collection by means of an Unmanned Aircraft System (UAS) with multi-camera ring, c) high resolution photo collection by a DSLR camera, and d) point clouds by a 3D TLS and the relevant equipment. During and following the data acquisition stage, quality control of all datasets was performed aiming to ensure the high quality of the results. Finally, the data processing and 3D modeling stages of the present methodology were carried out mainly by the application of the Structure from Motion computer vision algorithm.

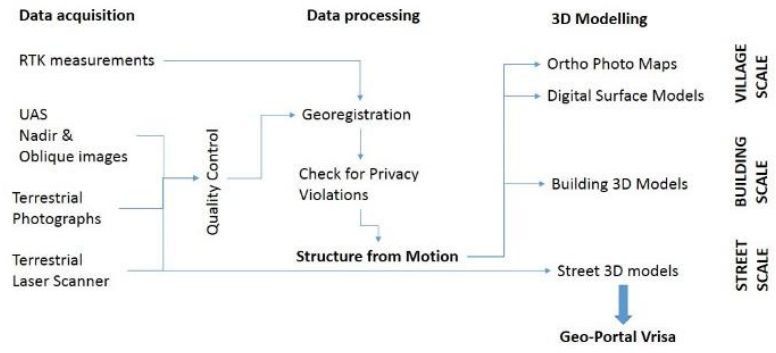

Figure 1. Flow chart of the methodology followed for the 3D mapping of Vrisa settlement after Lesvos earthquake at: i. village, ii. street and iii. building scales.

\subsection{Data acquisition}

The data acquisition campaign started on $13^{\text {th }}$ June 2017 , the very next day of the earthquake, under tough conditions and taking seriously into consideration the safety of the research team. During the next weeks, several very strong aftershocks occurred having magnitudes ranging from $3.5-5.0 \mathrm{Mw}$, producing wall collapsing during the campaign.

\subsubsection{RTK measurements}

Real Time Kinematics (RTK) is a differential Global Navigation Satellite System (GNSS) technique which achieves positional measurements with accuracy in the range of a few centimeters, in the vicinity of a base station. This technique is based on the use of carrier measurements and the transmission of corrections from a base station with known location, to the rover, so that the main errors that drive stand-alone positioning cancel out. The RTK base station covers an area extending about 10 kilometers, and a real time communication channel is necessary for connecting base and rover.

The first important step in the present methodology was the establishment of several Ground Control Points (GCPs) in Vrisa settlement with very high spatial accuracy and proper spatial distribution. These GCPs are necessary to enable georeferencing of all high-resolution aerial images as well as accurately identifying scan positions by the TLS. For this purpose, the following methodology was followed:

1. Two Base Stations (BS) were established within the village of Vrisa, depending on the base of the greek National Trigonometric Network (NTN) located at the top of the hill named Korona, SW of the settlement of Vrisa having coordinates $\mathrm{X}=689641.55 \mathrm{Y}=$ 4322030.77 and Altitude $=135.98$. Due to the morphology of the settlement, as it is developed on three hills and two flat relatively low altitude surfaces (Figure 2), the two BSs were placed on the 
two hills on the outskirts of the settlement in order to be higher than the rest set of GCPs to achieve better and more accurate measurements. The first BS was placed in the courtyard of the Primary School, $1.2 \mathrm{~km}$ away from the base of the NTN, with a horizontal error of $0.7 \mathrm{~cm}$ and an altitude error of $1.1 \mathrm{~cm}$. The second BS was placed very close and south of the metal bell tower, in front of the small church of the Cemetery of the settlement at a distance of $1.4 \mathrm{~km}$ from the base of the NTN, with a $0.9 \mathrm{~cm}$ horizontal and $1.5 \mathrm{~cm}$ elevation errors respectively (Table 1).

\begin{tabular}{cccccc} 
& Longitude & Latitude & $\begin{array}{c}\text { Altitude } \\
(\mathrm{m})\end{array}$ & $\begin{array}{c}\text { Horizontal } \\
\text { error }(\mathrm{cm})\end{array}$ & $\begin{array}{c}\text { Elevation } \\
\text { error } \\
(\mathrm{cm})\end{array}$ \\
\hline BS 1 & 4323057.15 & 690227.27 & 59.82 & 0.7 & 1.1 \\
\hline BS 2 & 4323343.99 & 690587.60 & 72.96 & 0.9 & 1.5 \\
\hline
\end{tabular}

Table 1. Geographical coordinates of the two Base Stations (BS).

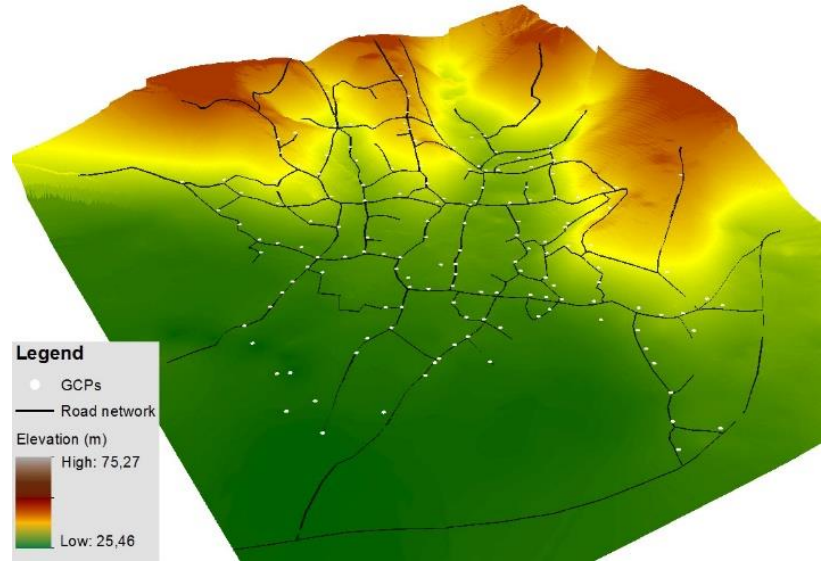

Figure 2. Digital Elevation Model of the study area, derived by kriging interpolation of the 157 RTK elevation measurements.

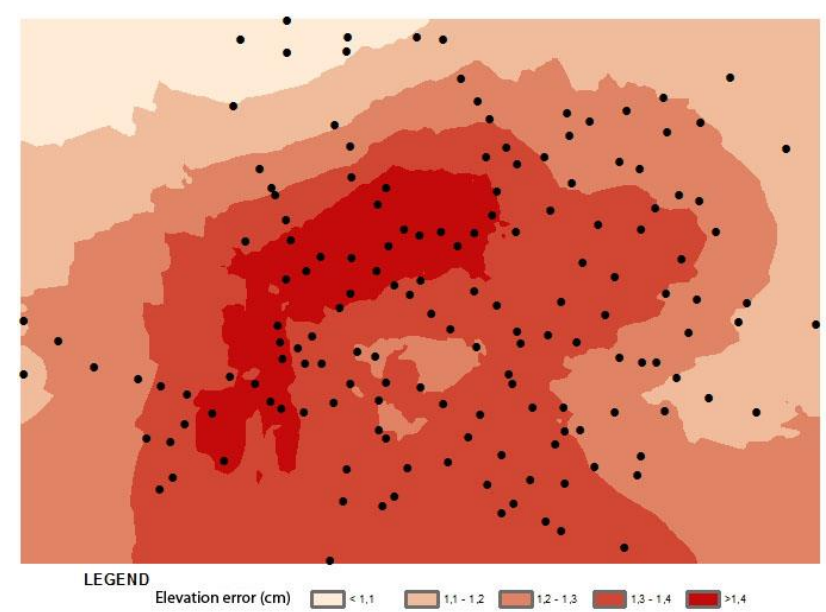

Figure 3. Spatial distribution of the elevation error by the 157 RTK measurements.

One hundred fifty seven (157) GCPs were placed within the Vrisa settlement, having very high accuracy in three dimensions (X, Y, $\mathrm{Z}$ ), with an RTK rover, the base of which was placed at the one of the two base points, depending on the area where the GCPs were placed, to achieve better reception and a greater number of satellites, with an average horizontal error of $0.8 \mathrm{~cm}$ and an average elevation error of $1.3 \mathrm{~cm}$ (Figure 3). The GCPs were marked on the ground, a red spray was used and a metal screw was placed in the center of the cross. Many of the points were placed on the metal caps of the drainage wells, while some points were not marked on the ground because of the collapse of buildings, but they were measured and used for georeferencing of the TLS positions. Thirty of the GCPs, were used for georeferencing the orthophoto maps, resulting from the UAS images, having a suitable spatial distribution in the settlement.

\subsubsection{UAS Nadir and Oblique high-resolution images}

The use of remote sensing in emergency situations offers several advantages, the first and foremost is the investigation and information acquisition in extremely hazard-prone zones. At first, for an 'early damage assessment', the high-resolution images are very useful to detect quickly the areas and structures that suffered the worst damages. For a complete and detailed survey of structures and infrastructures, useful for the following reconstruction phase, however, UAV photogrammetry is more suitable (Xu et al., 2014).

\begin{tabular}{|c|c|c|c|}
\hline \multirow[t]{4}{*}{ Flight } & Date & $13 / 06 / 2017$ & $25 / 07 / 2017$ \\
\hline & Time (local) & 12:30 p.m. & 12:00 p.m. \\
\hline & Duration & $35 \mathrm{~min}$ & 1h $20 \mathrm{~min}$ \\
\hline & Altitude & $160 \mathrm{~m}$. & $65 \mathrm{~m}$. \\
\hline Type of UAV & & $\begin{array}{l}\text { Hexacopter } \\
\text { one camera }\end{array}$ & $\begin{array}{l}\text { Hexacopter } \\
\text { multicamera } \\
\text { rig ( } 4 \text { cam) }\end{array}$ \\
\hline \multirow[t]{10}{*}{ Optical Sensor } & 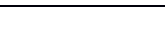 & Sony & Canon \\
\hline & camera & A5100 & IXUS 160 \\
\hline & $\begin{array}{l}\text { Effective } \\
\text { Pixels }\end{array}$ & $24.3 \mathrm{MP}$ & $20 \mathrm{MP}$ \\
\hline & Focal Length & $19 \mathrm{~mm}$ & $28 \mathrm{~mm}$ \\
\hline & & & $6.16 \mathrm{~mm}$ \\
\hline & Sensor & Width: $23.5 \mathrm{~mm}$ & \\
\hline & dimensions & Height: $15.6 \mathrm{~mm}$ & \\
\hline & & & $4.62 \mathrm{~mm}$ \\
\hline & $\begin{array}{l}\text { Pixel } \\
\text { dimension }\end{array}$ & $4.07 \times 4.07 \mu . \mathrm{m}$ & $1.2 \times 1.2 \mu . \mathrm{m}$ \\
\hline & $\begin{array}{l}\text { Weight } \\
\text { With Lens }\end{array}$ & $450 \mathrm{gr}$ & $127 \mathrm{gr}$ \\
\hline FOV direction & & UAS Nadir & $\begin{array}{c}\text { UAS: } \theta \\
=45^{\circ}\end{array}$ \\
\hline GSD & & $1.4 \mathrm{~cm} / \mathrm{pix}$ & $1.86 \mathrm{~cm} / \mathrm{pix}$ \\
\hline \multirow[t]{2}{*}{$\begin{array}{l}\text { Overlaping of } \\
\text { photographs }\end{array}$} & Longitudinal & $80 \%$ & $80 \%$ \\
\hline & Side lap & $70 \%$ & $80 \%$ \\
\hline $\begin{array}{l}\text { Number of } \\
\text { photographs }\end{array}$ & & Nadir: 229 & $\begin{array}{l}\text { Nadir: } 1044 \\
\text { Oblique: } \\
4805\end{array}$ \\
\hline Total area & & $0,346 \mathrm{Km} 2$ & $0,296 \mathrm{Km} 2$ \\
\hline
\end{tabular}

Table 2. Characteristics of the two main UAS flight surveys

During the present study a large amount of high resolution images were acquired using: a) a NIKKON D3400 camera, 
SDLR 24mpix crop, $18 \mathrm{~mm}$ focal length, b) four (4) cameras Sony A5100 (nadir) and three (3) Canon IXUS 160 onboard a hexacopter UAS, using an innovative noncommercial mutlicamera installation (Table 2). In more detail, the following survey plan was applied in order to acquire both terrestrial and aerial high-resolution images:

In less than 24 hours after the strong earthquake, a UAS (hexacopter) flew over the Vrisa village at $160 \mathrm{~m}$ altitude and captured vertical images using a Sony A5100 camera with a fixed lens of $19 \mathrm{~mm}$ focal length. During the period 13/07/20176/08/2017 a number of test flights (over 50) was carried out with various aerial means and a combination of sensors to achieve high-resolution mapping of the existing state of study area through the production of sub decimeter spatial resolution orthophoto maps. The mapping of the Vrisa village was carried out with flights at different heights so as to explore the most efficient parameters of collecting data to record the damages of the area's buildings in the optimal way. Almost one and a half month later, on $25^{\text {th }}$ July 2017 , an innovative noncommercial multicamera installation flew with a hexacopter, at a lower altitude $(65 \mathrm{~m})$, capturing high resolution images with: i.) one nadir and ii.) three (3) oblique cameras (angle $\theta=45^{\circ}$ ) located in bottom, front and left-right configuration on the UAS.

\subsubsection{Terrestrial high-resolution images}

Photogrammetry is a cost-effective means of obtaining largescale digital urban models. Photogrammetric techniques use 2D images without any a priori 3D data. Terrestrial, or ground-level, images are the most convenient data sources. Although these data provide high fidelity ground, vegetation, and building facade detail, they lack of building top information, and occlusion limits their range. The limited area visible in each image and the calibration needed to stitch images together makes it difficult to construct large urban areas. In order to meet the specific goal of creating 3D models not only of the affected by the earthquake buildings (damaged) but of the whole building stock of the Vrisa traditional settlement, the photographic planning was based on the following criteria:

i. Optimize the number of the photos for each building

ii. Maximize the accuracy of the information

iii. Avoid privacy violations

iv. Permit scale and registration of the $3 \mathrm{D}$ models

v. Account for safety issues.

Based on the above-mentioned criteria, during the period from $13^{\text {th }}$ of June 2017 to $6^{\text {th }}$ of July 2017, a survey for terrestrial highresolution image acquisition took place using two Nikon D3400 cameras with 24.2 MP resolution, $23.5 \times 15.6 \mathrm{~mm}$ sensor size and $6000 \times 4000$ pixel resolution, having the following common settings:

- $\quad$ Aperture mode (f / 8)

- $\quad$ Focal length: $18 \mathrm{~mm}$

- $\quad$ Production of raw JPEG images

- Vibration Reduction disabled

More specifically, the Vrisa settlement was divided into 238 road sections where each section included not more than five buildings (Figure 4) and about 20,000 photos were taken covering all the buildings of Vrisa village, taking into serious consideration that the post-earthquake activity was in progress and many aftershocks with magnitude $4-5$ were frequently occurring.

It is worth mentioning that photography on narrow-walled roads created a problem with the construction of a $3 \mathrm{D}$ model for tall buildings, due to the fact that a large percentage of the facade was either not visible due to a balcony or was visibly tilted to the level of the camera. Note that with the specific cameras and settings the size of the visible field (field of view) at a distance of 3 meters from a building is $3.92 \mathrm{~m} \times 2.6 \mathrm{~m}$. This caused a difficulty in matching at the photo algorithm because in such a small range it was often difficult to locate uniquely distinct spots to identify in more than one photograph. The existence of a smooth pattern such as the wall without any features or rectangular rails creates a problem in identifying the photos with each other. In some cases with no visible scale, measurements of distinct objects from the TLS data were used to determine the scale of the model.

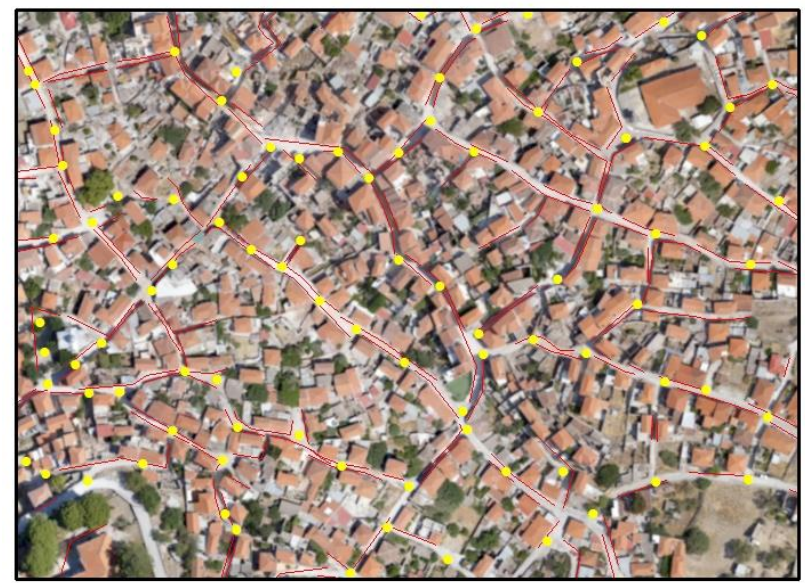

Figure 4 . The 240 sections of the terrestrial photograph and the 140 TLS positions campaigns.

\subsubsection{Terrestrial Laser Scanning}

Terrestrial Laser Scanning has proven to be an increasingly practical technology for providing precise, accurate, timely and non-destructive estimates of human and natural objects in 3D models. Operational acquisition of TLS data, at a village scale, is possible due to the reduced instrument costs, the improved range, precision and accuracy of measurements, as well as the increased capability of software and computing infrastructure to process large datasets.

The scan planning was designed with the aim of scanning not only the affected by the earthquake buildings (damaged) but the whole building stock of the Vrisa settlement. Taking into consideration the TLS technical specifications and the Vrisa settlement characteristics, a network of one hundred forty scanner positions were established (Figure 4), that allowed maximum coverage of the settlement and guaranteed a spatial resolution less than $1.5 \mathrm{~cm}$ for the whole settlement. The scan planning was also based on the following criteria:

$$
\begin{array}{ll}
\text { i. } & \text { Optimize the spatial distribution of the scans } \\
\text { ii. } & \text { Minimize the number of the TLS scans } \\
\text { iii. } & \text { Minimize as possible the occlusions } \\
\text { iv. } & \text { Avoid privacy violations (scan positions inside private } \\
\text { property) }
\end{array}
$$

Based on the criteria mentioned above, during the period from $13^{\text {th }}$ June 2017 to $06^{\text {th }}$ July 2017, a survey for TLS data acquisition performed by using a phase-shift laser scanner, FARO Focus ${ }^{3 \mathrm{D}}$. One hundred forty (140) laser scans were performed from pre-measured positions using the RTK 
technique, in the Greek reference system EGSA 87. The scans were conducted with the following settings on the laser scanner:

- Scan area: $360^{\circ}$ horizontally x $305^{\circ}$ vertically

- $1 / 4$ resolution that acquires point clouds at spatial resolution of $6.13 \mathrm{~mm} / 10 \mathrm{~m}$ and thus less than $1.5 \mathrm{~cm}$ for the whole scenario of the settlement

- $\quad$ digital compass and inclinometer measurements.

The combination of the measured scanner position with the measurements from the compass and the inclinometer offers the option of a sensor-driven method for georeferencing laser scanner data.

\subsection{Data Processing}

\subsubsection{Quality control}

After image acquisition, quality photo scans were followed to remove those that did not meet specific criteria, such as shifted scans as well as those in which there were objects in motion. Finally, the 3D Point Model acquired the texture of the buildings through the photos to create a photo-realistic object of the entire segment.

Visual inspection of all TLS data was performed in order to assess the quality of the point clouds. Scene software package by FARO (FARO, 2018) was used for the TLS data processing. The raw point clouds were cleaned from noise or undesired information such as vegetation. In cases where errors were detected (due to dust on the scanner's rotating mirror and passing vehicles), the specific scans were reshaped. Also, dozens of control distances were taken to objects in the area for comparison with digital models. These distances were taken on fixed objects (windows, doors, etc.) with a tape measure. Next, the accuracy of the scalability of the cloud point resulting from scanning with the TLS and the extent to which these measurements correspond to the actual sizes of the measured objects was determined.

\subsubsection{Geo-registration}

Geo-registration is a crucial step in order to provide absolute orientation and to assign the proper scale to all derivatives of the spatial data acquisition process, such as the orthorectified aerial high-resolution images, the point clouds etc. Thus, it is necessary to add an adequate number of GCPs measured, in the Greek reference system GRS-87, using the RTK technique (see Table 1). Subsequently, through the bundle adjustment, the GCPs together with the tie-points allow the internal and external orientation to be refined and directly obtain the geo-referenced model. Additionally, the geo-referenced 3D models must be verified using 'ground truth' measurements, several control points (CPs) (see Table 3) in order to meet the purpose of providing reliable and verified metric quantification, as required in the case of the post-earthquake damage assessment.

\begin{tabular}{ccccc} 
Flight & \multicolumn{2}{c}{$13 / 06 / 2017$} & \multicolumn{2}{c}{$25 / 07 / 17$} \\
\hline & Number & $\begin{array}{l}\text { Total } \\
\text { RMS }(\mathrm{cm})\end{array}$ & Number & $\begin{array}{l}\text { Total } \\
\text { RMS (cm) }\end{array}$ \\
\hline GCP & 10 & 7.3 & 20 & 2.3 \\
\hline
\end{tabular}

Table 3. List of the number and GCP's used and Total RMS.

As for the accuracy of the produced geoinformation (orthophotos and DSM) Table 3 depicts the values of the total RMS error for both data acquisition dates. More specifically, for the geo- registration of the first UAS survey (13/06/2017) 10 GCP's were used with a total RMS of $7.3 \mathrm{~cm}$.

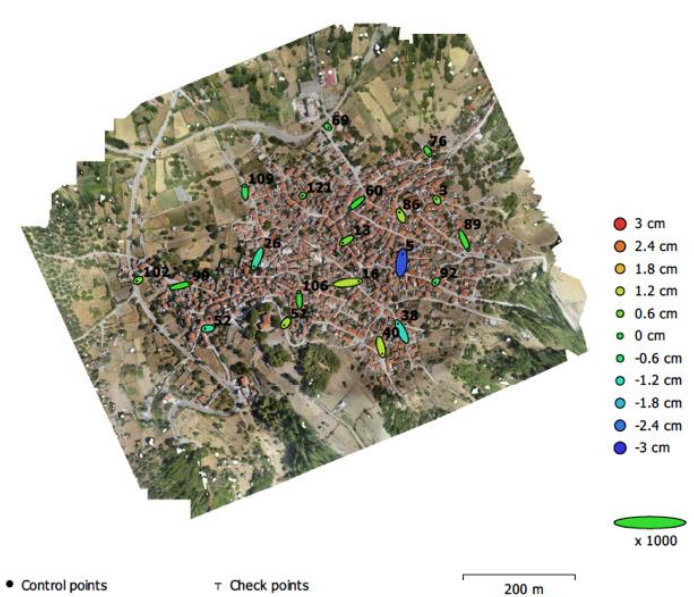

Figure 5. GCP locations and error estimates.

On the second UAS survey (25/07/2018) using the multicamera configuration, 20 GCP's were used with a total RMS of $2.3 \mathrm{~cm}$. The products generated for Vrisa village had geo-registration accuracies (RMS) less than a half of a pixel of the derivatives' resolution.

GCP locations and error estimates are depicted in Figure 5. The estimated GCP locations are marked with a dot and Z error is represented by a colored ellipse. Furthermore, X, Y errors are represented by elliptical shapes where the size of the ellipse for the major and minor axes represents the magnitude of $\mathrm{X}$ and $\mathrm{Y}$ errors respectively. From the geo-registration accuracy achieved, one can conclude that the precision of the geoinformation produced is of satisfactory accuracy for earthquake damage assessment.

\subsubsection{Check for Privacy Violations}

One of the main research concerns was the assurance of protecting the privacy of the individuals since it is a common threat to include personal identity in this kind of data sets accidentally. Thus, a detailed and systematic review of every element of the dataset was conducted for establishing and eliminating any form of violation of citizens' privacy through their direct or indirect identification from the data used. The examined data set included: i.) ground images taken with a camera, ii.) 3D models produced by TLS and by terrestrial photogrammetry, and iii.) photos taken by UAS flights. The methods applied for the protection of citizens' privacy were the following:

- Removal of citizens included in the data set

- Blurring of the parts of the images and models in cases where the specific parts could not be removed.

\subsubsection{D modeling with the SfM Algorithm}

The Structure from Motion algorithm, introduced in Computer Vision in the mid 90's, permits the automatic acquisition of the interior orientation parameters and the camera position in a relative image-space coordinate system. With SfM, scene geometry, camera position, interior and exterior orientation can all be extracted automatically, with high redundancy, using an iterative bundle adjustment (Triggs et al., 1999) on a sequence of images (multi-image approach). The principles and workflow of SfM have been described by Snavely (2011), Snavely et al. 
(2008) and Westoby et al. (2012). The Photoscan v1.3 software package (Agisoft, 2018) was used for the SfM photogrammetric processing, which can convert many images into georeferenced 2.5-D DSMs, digital orthophotos and 3D models.

When the SfM photogrammetric method is used to process the photographs that are captured by UAVs during emergency investigations of single geo-hazards, the results of the SfM photogrammetry should also be targeted to the different types or characteristics of the geo-hazard (Huang et al. 2017). Consequently, the results required for the specific postearthquake situation are: i.) DSMs; ii.) Orthophoto maps; and iii.) 3D models.

\section{RESULTS AND DISCUSSION}

The significant products obtained by the above described methodology were the following: i. orthophoto map and DSM (13 ${ }^{\text {th }}$ June 2017), ii. orthophoto map and DSM (25 ${ }^{\text {th }}$ July 2017), iii. Digital Elevation Model (DEM) of the broader area with spatial resolution $5 \mathrm{~cm}$ and vertical accuracy less than $1 \mathrm{~m}$, iv. two hundred forty (240) 3D models of all the buildings of Vrisa settlement, and v.) one hundred forty (140) 3D models from the TLS data.

The Orthophoto map (Figures 5,6) and DSM (Figure 7) produced by processing the 229 UAS aerial high-resolution images, which were obtained from flights at $160 \mathrm{~m}$ altitude, proved to be very efficient in 'early damage assessment'. Both products, obtained after few hours of processing due to a few photos, capture all the important information and give a clear view of the most damaged areas of the Vrisa settlement, as well as those that were not essentially affected. Collapsed and nearly collapsed buildings can be visually recognized, streets closed by collapsed building stone walls can be clearly seen, and even destroyed chimneys can easily identified. Based on the EMS-98 (Grünthal, 1998) damage classification on the specific results damages of: i.) Grade 5: destruction e.g. partial and total collapse of buildings and, ii.) Grade 4: very heavy damages e.g. heavy structural failure of roofs and floors can be visually identified giving a quick and accurate assessment of the earthquake devastation. Additionally, the DSM of Vrisa settlement (Figure 7) provides the most effective means to measure building heights and surfaces after the earthquake, giving an estimation of their volume, and the possible extent of their total or partial collapse.

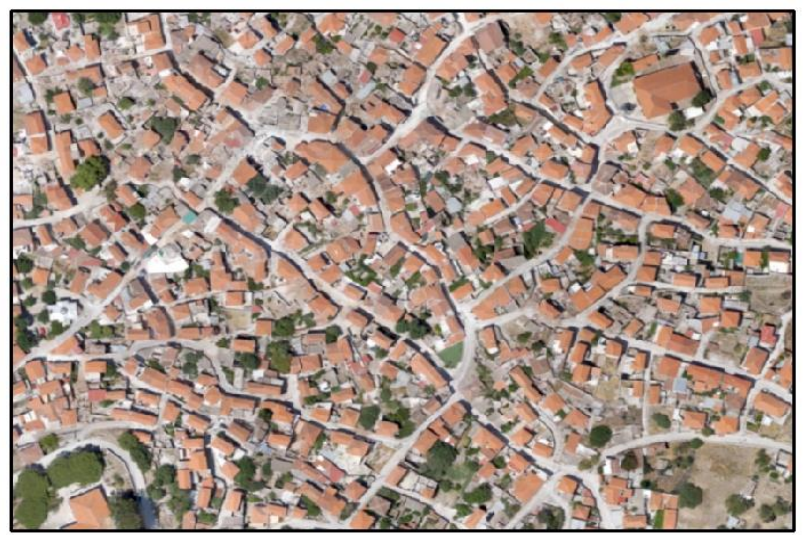

Figure 5. Orthophoto map of $13^{\text {th }}$ June 2017, scale: 1:4.000 illustrating damages of grade 5 e.g. partial and total collapse of buildings.

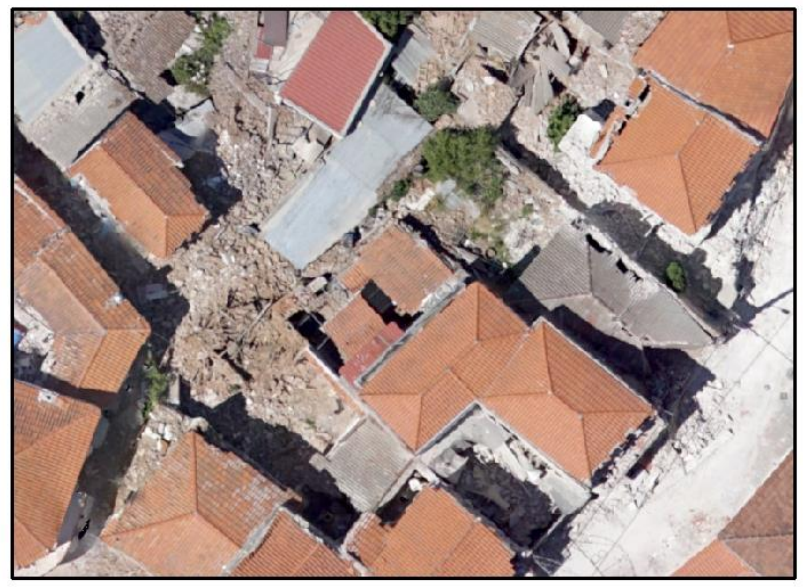

Figure 6. Part of the $13^{\text {th }}$ June 2017 orthophoto map at a scale of 1:500 with damages of grade 4 e.g. heavy structural failure of roofs and floors.

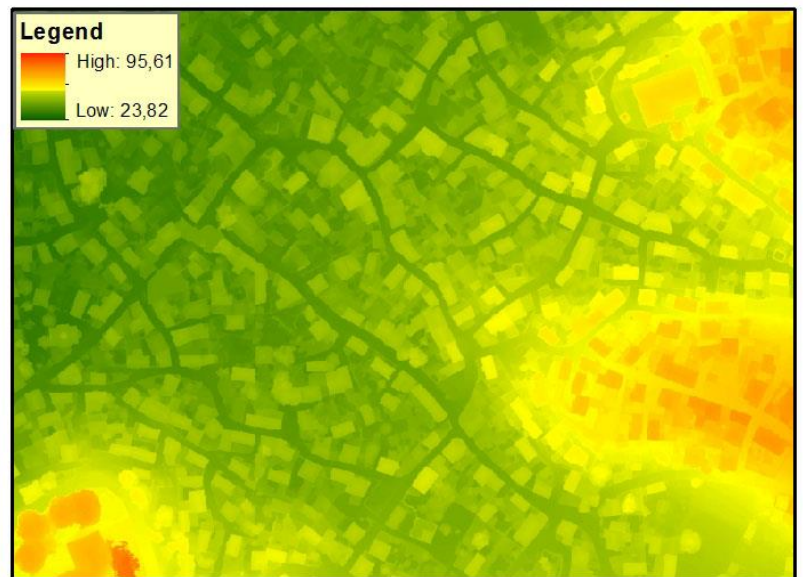

Figure 7. DSM for the $13^{\text {th }}$ of June 2017 , scale $1: 4.000$

The Orthophoto map (Figures 8, 9 and 10) and DSM, produced by processing the 1050 nadir and oblique UAS aerial highresolution images which flew at $65 \mathrm{~m}$ altitude, proved to be very effective for creating a 3D model at village scale (date: 25 July 2017). This 3D model (Figure 10) captures many of the building facades and as such it provides accurate information concerning the grade of damage occurred to buildings.

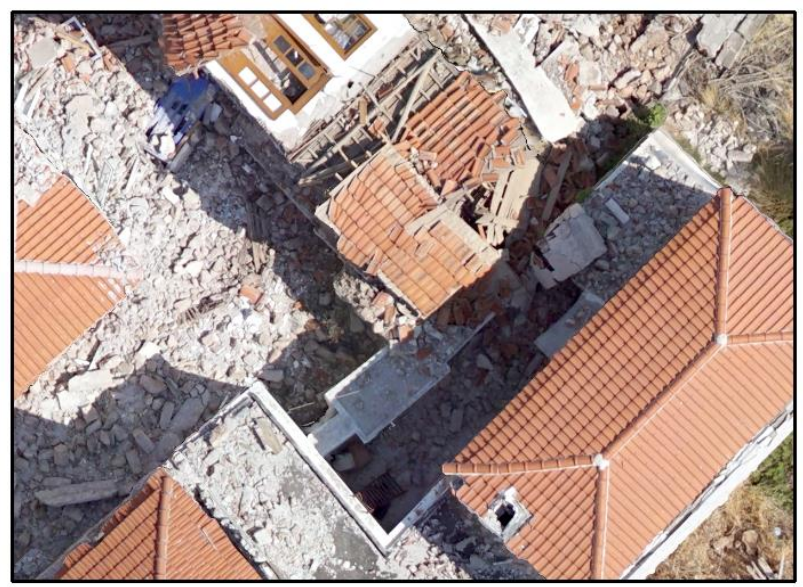

Figure 8 . Part of the $25^{\text {th }}$ July 2017 orthophoto map at a scale of 1:200 which clearly shows damages of grade 3 , e.g. dislocation and fall of roof tiles, detachment of the roof from the rest of the structure and fall of gables. 
Based on the EMS-98 (Grünthal, 1998) damage classification, on the specific orthophoto map, building damages, can be visually identified i.e. Grade 2: moderate damages e.g. cracks in many walls, detachment of small pieces of places from the walls and partial collapse of chimneys, and Grade 3: substantial to heavy damages e.g. large and extensive cracking of all masonry loadbearing walls, detachment of large pieces of plaster in all loadbearing walls, dislocation and fall of roof tiles, detachment of the roof from the rest of the structure and fall of gables. The results highlight the importance of applying suitable flight planning characteristics e.g. low altitude, more than one oblique cameras on board, in order to achieve more detailed and reliable 3D information (Figures 8 and 9).

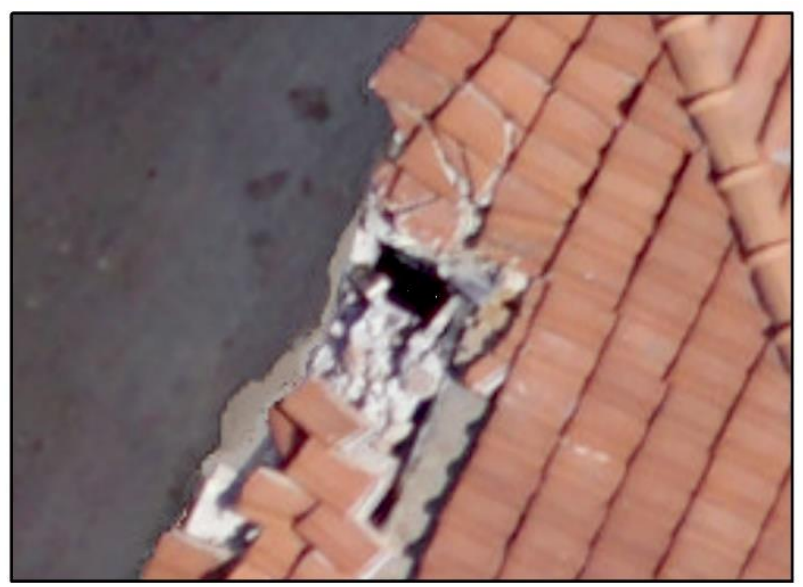

Figure 9. Part of the $25^{\text {th }}$ July 2017 orthophoto map at a scale of 1:40 which clearly shows damages of grade 2 on the top of the buildings, e.g. collapse of a chimney.

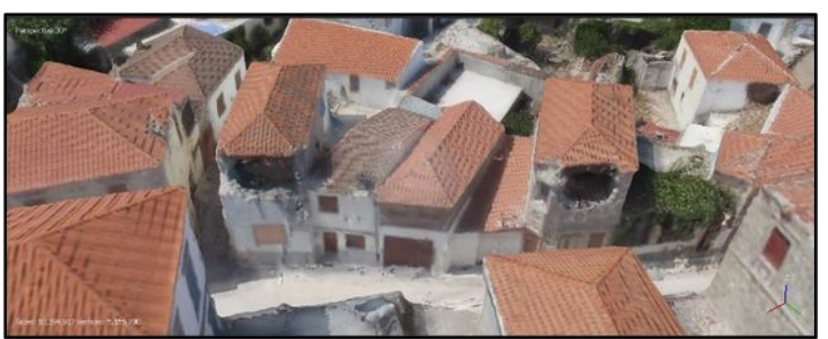

Figure 10. Part of the $25^{\text {th }}$ July 2017 3D model produced by nadir and oblique UAS-derived high-resolution images.

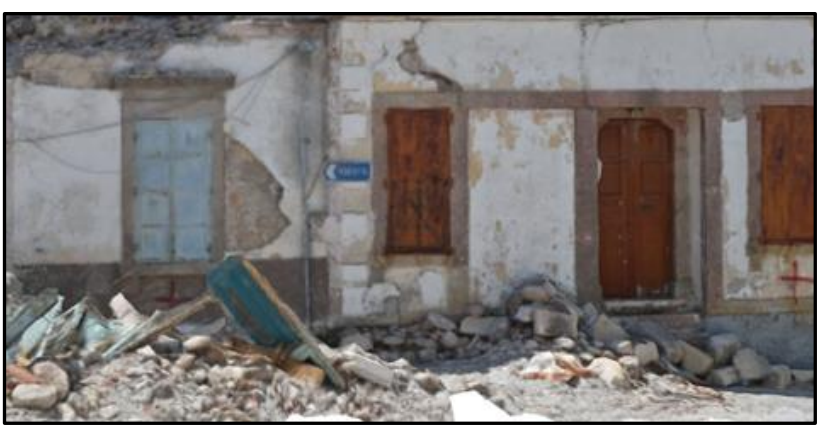

Figure 11. Part of a 3D model produced by terrestrial photogrammetry.

All the 240 3D models (Figure 11) and the 140 point clouds of the 3D laser scanner (Figure 12), created by terrestrial photogrammetry and TLS respectively, provide the most important 3D information for assessing damages of Grade 1: negligible to slight damages of the buildings. Their very high resolution and accuracy permit identifying hair-line cracks in walls, fall of small pieces of plaster only, falls of loose stones from upper parts of buildings.

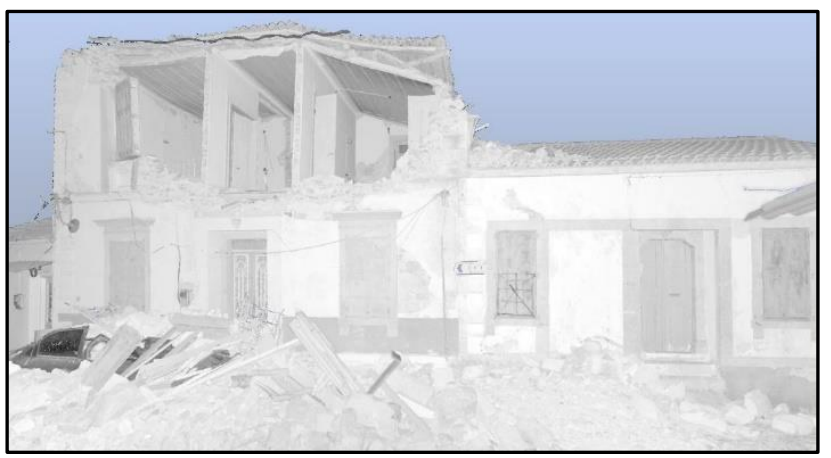

Figure 12. Part of a TLS 3D model with intensity values.

\subsection{Geoportal}

Within the context of this research project, there was also a need for sound management and visualization of a large volume of final products. In addition, there existed a need to visualize their spatial distribution so that they could be asynchronously and remotely studied. For this purpose, it was considered necessary to design and implement an online geoportal which is hosted on a server, accessible only by authorized users. The design took into account the needs of the research project to monitor the initial data, as well as the need for online visualization of the final data from each subgroup. The technologies used to construct the geoportal consisted of a number of programming languages for the construction of data structures, by server-side technologies and by client-side technologies. The technologies used included the PHP and Python programming languages. The management of the complex geo-data structures in the embedded GeoServer and the database has been achieved by using Postgresql as it offers spatial data structures management capabilities.

Visualization was implemented through hypertext files that include Html, AJAX, and Javascript. Lastly, the orthophoto map service was implemented using Tile Map Services for better performance, taking into account the low internet access speeds without, however, reducing the quality of visualization of the final deliverable.

Finally, considering the multitude of users who will access the geoportal, as well as the variety of devices to be used (pc, tablet, mobile) special care was taken to make the geoportal accessible from any of the latest technologies without reducing its efficiency and functionality.

\section{CONCLUSIONS}

The main conclusion from the present study is the ability to simultaneously map a post-disaster situation at three spatial scales: i.) a village-scale, ii.) street-scale, and ii.) building-scale. The ambitious goal was to tackle all the difficulties of a postearthquake scenario, in order to apply 3D mapping methodologies simultaneously to all three different scales. All scales are important in order to document the damages occurred to the Vrisa traditional settlement, by providing metrical information to permit building damage assessment according to the five (5) EMS-98 damage classification grades. The fact that 
geoinformation, in a post-earthquake scenario, provides a great spectrum of methods, techniques and algorithms to calculate and measure 3D information, in three spatial scales, proved to be promising for further research and development of semi or fully automatic methodologies.

Additionally, TLS 3D models were identified as the most effective means to assess building damages of grade 1 . From the present study, it is obvious that terrestrial photogrammetry also provides very high accurate $3 \mathrm{D}$ models, capturing the morphological characteristics that permit assessing damages of grades 1, 2 and 3. These 3D models of the damaged buildings, record in the most efficient way all the consequences of the earthquake before any human activity changes them, e.g. risklifting processes. In parallel, UAS derived orthophoto maps and DSMs can serve in an early damage assessment process by providing information concerning mainly building damages of grades 4 and 5 .

Finally, all 3D models would be useful for a post-earthquake management and reconstruction processes. In addition, 3D mapping of an earthquake damaged traditional settlement is of great importance because after a short period the majority of the heavily damaged building will be demolished, destroying all their morphological characteristics, including their construction material and morphology of a traditional house. This 3D information can serve all stakeholders, national and local organizations focusing on the post-earthquake management and reconstruction processes of the Vrisa traditional village.

\section{ACKNOWLEDGEMENTS}

This paper is a result of the research project "3D mapping of Vrisa settlement after the $12^{\text {th }}$ June Lesvos earthquake" funded by the North Aegean Region. The authors would like to thank Professor Pavlogeorgatos G., Doukari M., Drolias A., Mauroeidi A., Zorbas K., Papazis N., Moustakas, A. and Makri D. for supporting the processing stage of this project.

\section{REFERENCES}

Adams, S.M. and Friedland, C.J., 2011. A survey of unmanned aerial vehicle (UAV) usage for imagery collection in disaster research and management, In: 9th International Workshop on Remote Sensing for Disaster Response, Stanford University, California, USA.

Agisoft, 2018. Agisoft PhotoScan User Manual, Professional Edition, Version 1.3, http://www.agisoft.com/pdf/photoscanpro_1_3_en.pdf (7 February 2018).

Chatzipetros, A., Kiratzi, A., Sboras, S., Zouros, N., and Pavlides, S., 2013. Active faulting in the north-eastern Aegean Sea Islands. Tectonophysics, 597-598, pp. 106-122.

Dominici, D., Alicandro M., and Massimi, V., 2017. UAV photogrammetry in the post-earthquake scenario: case studies in L'Aquila. Geomatics, Natural Hazards and Risk, 8(1), pp. 87103 https://doi.org/10.1080/19475705.2016.1176605

FARO, 2018. FARO SCENE: FARO's 3D Documentation Software for terrestrial and handheld Scanners, Version 7.0, https://www.faro.com/products/product-design/faro-scene/ (7 February 2018).
Grünthal, G. (ed) 1998. European Macroseismic Scale 1998 (EMS-98). Chaiers du Centre Européen de Géodynamique et de Séismologie, 15, Luxembourg.

Huang, H, Long, J, Yi, W, Yi, Q, Zhang, G, and Lei, B., 2017. A method for using unmanned aerial vehicles for emergency investigation of single geo-hazards and sample applications of this method. Natural Hazards and Earth System Sciences, 17(11), pp. 1961-1979 https://doi.org/10.5194/nhess-17-1961$\underline{2017}$

Kiratzi, A., 2018. The 12 June 2017 Mw 6.3 Lesvos Island (Aegean Sea) earthquake: Slip model and directivity estimated with finite-fault inversion. Tectonophysics, 724-725, pp. 1-10 https://doi.org/10.1016/j.tecto.2018.01.003

Lekkas, E., Carydis, P., Skourtsos, E., Mavroulis, S., Andreadakis, E., Antoniou, V., and Spyrou, N, 2017. Factors controlling the distribution of building damage in the traditional Vrissa settlement induced by the 2017 June 12, Mw 6.3 Lesvos (Northeastern Aegean Sea, Greece) earthquake. In: $8^{\text {th }}$ International INQUA Meeting on Paleoseismology, Active Tectonics and Archeoseismology (PATA), 13-16 November, 2017, New Zealand.

Novak, I. and Soulakellis, N., 2000. Identifying geomorphic features using LANDSAT-5/TM data processing techniques on Lesvos, Greece. Geomorphology, 34(1-2), pp. 101-109 https://doi.org/10.1016/S0169-555X(00)00003-9

Snavely, N., 2011. Scene reconstruction and visualization from Internet photo collections. IPSJ Transactions on Computer Vision and Applications, 3, pp. 44-66 https://doi.org/10.2197/ipsitcva.3.44

Snavely, N., Seitz, S.M., and Szeliski, R. 2008. Modeling the world from Internet photo collections. International Journal of Computer Vision, 80(2), pp. 189-210 https://doi.org/10.1007/s11263-007-0107-3

Soulakellis, N., Novak, I., Zouros, N, Lowman, P. and Yates, J. 2006. Fusing Landsat-5/TM imagery and shaded relief maps in tectonic and geomorphic mapping: Lesvos Island, Greece. Photogrammetric Engineering and Remote Sensing, 72(6), pp. 693-700.

Triggs, W., McLauchlan, P., Hartley, R., and Fitzgibbon, A., 1999. Bundle adjustment: A modern synthesis. In: Vision Algorithms: Theory and Practice, number 1883 in LNCS. Springer-Verlag. Corfu, Greece, pp. 298-373.

Wegscheider, S., Schneiderhan, T., Mager, A., Zwenzer, H., Post, J., Strunz, G., 2013. Rapid mapping in support of emergency response after earthquake events. Natural Hazards, 68(1), pp. 181-195 https://doi.org/10.1007/s11069-013-0589-y

Westoby, M.J., Brasington, J, Glasser, N.F., Hambrey, M.J., and Reynolds J.M., 2012. Structure-from-motion' photogrammetry: A low-cost, effective tool for geoscience applications. Geomorphology, 179, pp. 300-314.

Xu, Z., Yang, J., Peng, C., Wu, Y., Jiang, X., Li, R., Zheng, Y., Gao, Y., Liu, S., Tian, B., 2014. Development of an UAS for post-earthquake disaster surveying and its application in Ms7.0 Lushan Earthquake, Sichuan, China. Computers and Geosciences, 68, pp. 22-30 https://doi.org/10.1016/j.cageo.2014.04.001 